\title{
Experimental Engineering and Applications
}

\author{
A. Öchsner • L.F.M. da Silva
}

Published online: 14 April 2010

(C) Society for Experimental Mechanics 2010

This special issue of Experimental Mechanics contains selected papers presented at the 2nd International Conference on Advanced Computational Engineering and Experimenting (ACE-X 2008) held at Hotel Meliã (Barcelona), Spain during the period 14th-15th July, 2008.

During the conference, a special session related to Adhesive Bonding (organised by Prof. Lucas Filipe Martins da Silva and Prof. Juan Carlos Suárez Bermejo) was held. In addition, three short courses related to Modelling and Testing of Cellular Materials (organised by Prof. Andreas Öchsner), Structural Hybrid Materials: Biomimetism and Bioinspiration (organised by Prof. Juan Carlos Suárez Bermejo) and Structural Analysis in Vehicle Engineering (organised by Prof. Markus Merkel) were held.

This issue contains full length manuscripts covering a wide range of topics in experimental engineering. The contribution by Shahani et al. is related to the fatigue crack growth in pipes under cyclic bending loads. In their work, experiments are compared to numerical results obtained from finite element simulation. Radnić and Matešan report the long-term behaviour of steel-reinforced concrete shells under static loading. The fracture evaluation in a dome port under shock impact is experimentally investigated by Kwon et al. and compared to numerical simulations. Dubois and co-workers report on the design of a testing rig to investigate the tag of carbon-epoxy prepregs. Johani and Nobari apply neural networks and modal data to investigate the dynamic behaviour of a structural adhesive. Shim et al. analyse the residual stresses in thick-walled cylinders considering the Bauschinger effect. Cardoso et al. present an inverse analysis to identify parameters of the Gurson damage model. Choi et al. investigate the nano-scale elastic modulus of thin Pt films based on the wrinkle pattern of buckled films whereas Lee et al. investigate thin $\mathrm{Au}$ films based on the microtensile test. Ren and co-workers analyse the elastic deformation of materials under distributed shear loads while the work by Lee et al. studies the biomechanical problem of dorsiflexion under eccentric exercise.

We would like to express our sincere appreciation to the representatives of the Society for Experimental Mechanics, in particular to Professor H.D. Espinosa, Editor-in-Chief of Experimental Mechanics and Ms. Jennifer Tingets, Managing Editor, who made this special issue possible. We also wish to express our gratitude to our colleagues, associates and friends for their sustained assistance, help and enthusiasm during the preparation of the conference and this special issue.

\footnotetext{
A. Öchsner $(\bowtie)$

Department of Applied Mechanics,

Technical University of Malaysia-UTM, 81310 UTM Skudai,

Johor, Malaysia

e-mail: andreas.oechsner@gmail.com

L.F.M. da Silva

Departamento de Engenharia Mecânica, Faculdade de Engenharia,

Universidade do Porto,

Rua Dr. Roberto Frias,

4200-465 Porto, Portugal

e-mail: lucas@fe.up.pt
} 